\title{
EDITORIAL
}

\section{Titanium and gold nanoparticles in asthma: the bad and the ugly}

\author{
S. Lanone*,\# and J. Boczkowski*,\#, ,
}

D ngineered nanomaterials (ENMs) are defined as having at least one dimension $\leqslant 100 \mathrm{~nm}$ [1]. When ENMs have three dimensions $\leqslant 100 \mathrm{~nm}$ they are called nanoparticles (NPs). ENMs have attracted a great deal of attention recently because their many technologically interesting properties have led to technological growth with ensuing economic rewards [2]. Technologies involving ENMs are envisaged to become the cornerstone for a number of industrial sectors, such as microelectronics, materials, paper, textiles, energy, cosmetics and medical devices, all capable of incorporating some nanoscaleenabled properties into their products [2]. By 2015, the annual profit from ENM-based products is estimated to be US\$1.1-2.5 trillion [3]. Today, ENMs can be found in more than 1,000 consumer products [4]. By 2015, 2 million workers will be needed to support nanotechnology industries worldwide [5]. However, some of the properties of ENMs that are unique and beneficial for technological applications may also endanger human health, inducing cyto- and genotoxic effects, inflammation and even cancer [6-12]. Inflammatory effects are particularly important [13-15]. Free radical activity or oxidative capacity of particulate matter might be essential for provoking these inflammatory responses.

The physico-chemical features of ENMs that account for their deleterious health effects include a large ratio of surface area to mass and associated increased surface reactivity, altered physico-chemical properties, such as changes in melting point, solubility or electrical conductivity, or changes, for example, in the crystalline structure of the materials [16-20]. Therefore, detailed evaluation of these characteristics is critical for the understanding of the mechanisms by which ENMs elicit biological responses.

The respiratory system is a critical route of exposure to aerosolised ENM, by accident or by occupational exposure. A rapidly increasing number of studies have evaluated the respiratory effects of ENMs in different animal models [21-23]. However, few of these studies have investigated the effects of respiratory ENMs in models of respiratory disease. This lack of investigation is important because 1) workers or users of ENMs can have respiratory diseases, and 2) previous

\footnotetext{
*INSERM U955 and Université Paris Est Val de Marne (UPEC), ${ }^{*}$ Service de pneumologie e pathologie professionnelle, Hôpital Intercommunal de Créteil and "Service de Physiologie Explorations Fonctionnelles, AP-HP, Hôpital Henri Mondor, Créteil, France.

CORRESPONDENCE: J. Boczkowski, INSERM U955 Eq04, 8 rue du Géneral Sarrail, Créteil F-94010, France. E-mail: jorge.boczkowski@inserm.fr
}

studies of air pollution particles with similar dimensions as those of ENMs (called "ultrafine particles") have been shown to aggravate pulmonary diseases [24]. For example, PENTTINEN et al. [25] showed that the concentration of particles in ambient air, especially those in the ultrafine range, were negatively associated with the respiratory health of adults with asthma.

In the current issue of the European Respiratory Journal, HUSSAIN et al. [26] report, for the first time, on the effects of two ENMs, titanium dioxide $\left(\mathrm{TiO}_{2}\right)$ and gold $(\mathrm{Au}) \mathrm{NPs}$, in a murine model of toluene-2,4-diisocyanate-induced asthma. NPs were administered by oropharyngeal aspiration after repeated dermal sensitisation to diisocyanate. The day after NP administration, animals were oropharyngeally challenged with diisocyanate, and the next day, airway reactivity to metacholine was measured and bronchoalveolar lavage (BAL) inflammation and lung histological features were analysed. The dose of NPs, based on the current time-weighted average (TWA) values for a single shift in $\mathrm{TiO}_{2}$ level, was $16 \mu \mathrm{g}$ for a mouse weighing $20 \mathrm{~g}$.

The main results of the study can be classified into three groups: 1) effects of diisocyanate sensitisation and challenge not modified by either one of the two NPs (increase in matrix metalloproteinase-9 in BAL, increase in serum immunoglobulin E levels, increase in BAL eosinophils, increase in airway hyperresponsiveness (AHR; only in the case of $\mathrm{TiO}_{2}$ ); 2) effects induced by both NPs in diisocyanate-sensitised and -challenged animals (increase in macrophage inflammatory protein-2 in $\mathrm{BAL}$, increase in macrophages and neutrophils in BAL, lung macrophages infiltration); and 3) effects induced only by $\mathrm{Au}$ NPs in diisocyanate-sensitised and -challenged animals (potentiation of the increase in AHR, diminished tumour necrosis factor (TNF) secretion in BAL, and lung tissue oedema and epithelial damage). The last two types of effects of NPs were not observed in animals not exposed to diisocyanate. The last two types of effects were not observed in animals not exposed to diisocyanate.

Therefore, both NPs modified some features of the diisocyanate-induced asthma model: $\mathrm{TiO}_{2}$ NPs induced lung macrophage and neutrophil recruitment without affecting AHR, whereas Au NPs induced these effects along with lung tissue oedema, epithelial damage and potentiation of AHR. Neither NP induced biological responses in nonsensitised and challenged animals. Taken together, these results are very interesting and open new areas of research in the field of nanotoxicology. 
Several points can be discussed concerning this study. The first is the relevance of the dose of NPs examined. This dose $\left(0.8 \mathrm{mg} \cdot \mathrm{kg}^{-1}\right)$, based on exposure conditions of workers, is in the lower range of doses currently used in different studies, at least for $\mathrm{TiO}_{2}\left(1-5 \mathrm{mg} \cdot \mathrm{kg}^{-1}\right)$. This dose can explain that, in absence of diisocyanate administration, $\mathrm{TiO}_{2} \mathrm{NPs}$ did not elicit any inflammatory effect and did not modify airway reactivity, which agrees with previous data from WARHEIT et al. [27]. The rationale of the authors' choice of dose (extrapolation of current TWA values for a single shift in $\mathrm{TiO}_{2}$ level) is clearly relevant in terms of worker exposure. This point is important because it means that respiratory exposure to ENMs does not always induce lung inflammation, at least in a short-term evaluation. However, the question still remains regarding accumulation of ENMs after repeated exposure. Moreover, the metric of particle exposure is under discussion [28, 29]. Indeed, in addition to "mass" (as used in the present study), and taking into account the various physico-chemical features of ENMs involved in deleterious health effects described before, ENM particle surface area has been suggested as appropriate for evaluating ENM exposure, and may result in a meaningful dose-effect curve [30]. However, this measurement has not been evaluated in animal models of disease, in which the mechanism(s) of action of ENMs could differ from those underlying their effects in healthy animals. Experimental models such as that used by HUSSAIN et al. [26] could help determine whether particle surface area and/or number could be used when analysing the effects of ENMs in the context of respiratory diseases.

As HussAin et al. [26] mention, few data are available on the effects of pulmonary exposure to $\mathrm{Au}$ NPs and, therefore, understanding all the implications of their findings is difficult, particularly the difference they observed between the $\mathrm{Au}$ and $\mathrm{TiO}_{2}$ effects, although both NPs were similarly internalised by macrophages. One explanation for the difference could be a pro-autophagic effect of Au NPs [31], which has not yet been reported for $\mathrm{TiO}_{2}$ NPs. Autophagy is an evolutionarily conserved simple process by which cells target their own cellular organelles and long-lived protein degradation. Autophagy has recently been shown to be involved in many biological aspects, including host defence, cell survival and death, cancer, and innate and adaptive immunity [32]. Au-induced autophagy of epithelial cells could explain the epithelial damage, oedema and increase in AHR HUSSAIN et al. [26] observed. Autophagy is regulated by various T-helper (Th) type 1 and Th2 cytokines such as interferon- $\gamma$, interleukin (IL)-4 and IL-13 that are involved in asthma. The authors did not measure the levels of these cytokines, although the absence of change in BAL eosinophil numbers in their animal model of asthma with administration of both NPs argues against an increase in production of IL-4. However, examining the occurrence of autophagy in this animal model of asthma with administration of both NPs would be interesting, as would quantifying the levels of the cytokines involved in the induction of autophagy in the model of asthma used by HUSSAIN et al. [26], particularly in the auricular lymph nodes. Indeed, previous work has demonstrated that in this model, BAL is not the most relevant compartment to look at [33].

Of note, the only cytokine whose expression was modulated by NP administration in the HUSSAIN et al. [26] model of asthma was TNF- $\alpha$, whose expression was downregulated after Au NP administration. This finding is intriguing, because these animals showed an increase in AHR, whereas asthmatic animals receiving $\mathrm{TiO}_{2}$ NPs did not. Furthermore, TNF- $\alpha$ levels are increased in patients with asthma [34]. This result suggests that TNF- $\alpha$ does not play a role in the increase in AHR elicited by Au NPs. In accordance, anti-TNF strategies with initial promise in asthma were found effective in only a relatively small subgroup of patients with severe asthma [34], thus ruling out a unique role for TNF in the pathophysiology of asthma. The mechanism(s) of the downregulation of TNF- $\alpha$ by $\mathrm{Au}$ NPs remains to be elucidated.

In conclusion, the study reported by Hussain et al. [26] in this issue shows evidence of the potential aggravating effects of NPs in the context of chemically induced occupational asthma and opens new doors into gaps in knowledge that need to be filled by further studies, in order to better understand the underlying mechanisms of these effects.

\section{STATEMENT OF INTEREST}

None declared.

\section{REFERENCES}

1 Oberdorster G, Oberdorster E, Oberdorster J. Nanotoxicology: an emerging discipline evolving from studies of ultrafine particles. Environ Health Perspect 2005; 113: 823-839.

2 Linkov I, Steevens J, Adlakha-Hutcheon G, et al. Emerging methods and tools for environmental risk assessment, decisionmaking, and policy for nanomaterials: summary of NATO Advanced Research Workshop. J Nanopart Res 2009; 11: 513-527.

3 Lux Research. Nanotech Report, 4th Edn. The Indispensable Reference Guide to Nanotechnology. New York, 2006. www. luxresearchinc.com/press/RELEASE_TNR4.pdf

4 Woodrow Wilson International Centre for Scholars, Project on Emerging Nanotechnologies. www.wilsoncenter.org Date last accessed: November 23, 2010. Date last updated: August 9, 2010.

5 National Nanotechnology Initiative. FAQs: Nanotechnology. www. nano.gov/html/facts/faqs.html Date last accessed: November 23, 2010. Date last updated: July 7, 2010.

6 Donaldson K, Tran L, Jimenez LA, et al. Combustion-derived nanoparticles: a review of their toxicology following inhalation exposure. Part Fibre Toxicol 2005; 2: 10.

7 Lanone S, Boczkowski J. Biomedical applications and potential health risks of nanomaterials: molecular mechanisms. Curr Mol Med 2006; 6: 651-663.

8 Yang W, Peters JI, Williams RO 3rd, Inhaled nanoparticles: a current review. Int J Pharm 2008; 356: 239-247.

9 Bussy C, Cambedouzou J, Lanone S, et al. Carbon nanotubes in macrophages: imaging and chemical analysis by X-ray fluorescence microscopy. Nano Lett 2008; 8: 2659-2663.

10 Tabet L, Bussy C, Amara N, et al. Adverse effects of industrial multiwalled carbon nanotubes on human pulmonary cells. J Toxicol Environ Health A 2009; 72: 60-73.

11 Mroz RM, Schins RP, Li H, et al. Nanoparticle-driven DNA damage mimics irradiation-related carcinogenesis pathways. Eur Respir J 2008; 31: 241-251.

12 Song Y, Li X, Du X. Exposure to nanoparticles is related to pleural effusion, pulmonary fibrosis and granuloma. Eur Respir J 2009; 34: 559-567.

13 Stone V, Johnston $\mathrm{H}$, Clift MJ. Air pollution, ultrafine and nanoparticle toxicology: cellular and molecular interactions. IEEE Trans Nanobioscience 2007; 6: 331-340. 
14 Tsuji JS, Maynard AD, Howard PC, et al. Research strategies for safety evaluation of nanomaterials, part IV: risk assessment of nanoparticles. Toxicol Sci 2006; 89: 42-50.

15 Wittmaack K. In search of the most relevant parameter for quantifying lung inflammatory response to nanoparticle exposure: particle number, surface area, or what? Environ Health Perspect 2007; 115: 187-194.

16 Elder A, Vidyasagar S, DeLouise L. Physicochemical factors that affect metal and metal oxide nanoparticle passage across epithelial barriers. Wiley Interdiscip Rev Nanomed Nanobiotechnol 2009; 1: 434-450.

17 Borm PJ, Robbins D, Haubold S, et al. The potential risks of nanomaterials: a review carried out for ECETOC. Part Fibre Toxicol 2006; 3: 11.

18 Nel A, Xia T, Madler L, et al. Toxic potential of materials at the nanolevel. Science 2006; 311: 622-627.

19 Maynard AD. Nanotechnology: the next big thing, or much ado about nothing? Ann Occup Hyg 2007; 51: 1-12.

20 Maynard AD, Aitken RJ, Butz T, et al. Safe handling of nanotechnology. Nature 2006; 444: 267-269.

21 Chen Z, Meng H, Xing G, et al. Acute toxicological effects of copper nanoparticles in vivo. Toxicol Lett 2006; 163: 109-120.

22 Trouiller B, Reliene R, Westbrook A, et al. Titanium dioxide nanoparticles induce DNA damage and genetic instability in vivo in mice. Cancer Res 2009; 69: 8784-8789.

23 Chen HW, Su SF, Chien CT, et al. Titanium dioxide nanoparticles induce emphysema-like lung injury in mice. FASEB J 2006; 20: 2393-2395.

24 Frampton MW, Utell MJ, Zareba W, et al. Effects of exposure to ultrafine carbon particles in healthy subjects and subjects with asthma. Res Rep Health Eff Inst, 2004: 1-47.
25 Penttinen $\mathrm{P}$, Timonen KL, Tiittanen $\mathrm{P}$, et al. Ultrafine particles in urban air and respiratory health among adult asthmatics. Eur Respir J 2001; 17: 428-435.

26 Hussain S, Vanoirbeek JAJ, Luyts K, et al. Lung exposure to nanoparticles modulates an asthmatic response in a mouse model. Eur Respir J 2011; 37: 299-309.

27 Warheit DB, Webb TR, Sayes CM, et al. Pulmonary instillation studies with nanoscale $\mathrm{TiO}_{2}$ rods and dots in rats: toxicity is not dependent upon particle size and surface area. Toxicol Sci 2006; 91: 227-236.

28 Muhlfeld C, Rothen-Rutishauser B, Blank F, et al. Interactions of nanoparticles with pulmonary structures and cellular responses. Am J Physiol Lung Cell Mol Physiol 2008; 294: L817-L829.

29 Pauluhn J. Comparative pulmonary response to inhaled nanostructures: considerations on test design and endpoints. Inhal Toxicol 2009; 21: Suppl. 1, 40-54.

30 Oberdorster G, Maynard A, Donaldson K, et al. Principles for characterizing the potential human health effects from exposure to nanomaterials: elements of a screening strategy. Part Fibre Toxicol 2005; $2: 8$.

31 Li JJ, Hartono D, Ong C-N, et al. Autophagy and oxidative stress associated with gold nanoparticles. Biomaterials, 31: 5996-6003.

$32 \mathrm{Xu} \mathrm{Y,} \mathrm{Eissa} \mathrm{NT.} \mathrm{Autophagy} \mathrm{in} \mathrm{innate} \mathrm{and} \mathrm{adaptive} \mathrm{immunity.} \mathrm{Proc}$ Am Thorac Soc, 7: 22-28.

33 De Vooght V, Vanoirbeek JAJ, Haenen S, et al. Oropharyngeal aspiration: an alternative route for challenging in a mouse model of chemical-induced asthma. Toxicology 2009; 259: 84-89.

34 Matera MG, Calzetta L, Cazzola M. TNF- $\alpha$ inhibitors in asthma and COPD: we must not throw the baby out with the bath water. Pulm Pharmacol Ther, 23: 121-128. 